\title{
MJN \\ CORRELATION OF ADMISION TIME, DISCHARGE TIME AND PATIENTS DISCHARGE TYPE WITH LENGTH OF STAY IN YELLOW ZONE OF EMERGENCY DEPARTMENT
}

\author{
Manggar Purwacaraka*, Ahsan Ahsan, Tina Handayani Nasution \\ ${ }^{1}$ Nursing Master Program, University of Brawijaya, Indonesia \\ *Corresponding Author's Email: manggar.com@gmail.com
}

\begin{abstract}
Background: The number of patients continues to increase each year in Emergency Department (ED), especially in Priority 2 / Yellow Zone. The ED cannot predict patient's condition and when the patient comes for admission the time is various. The ED overcrowding is correlated with discharge time, whereas discharge time is correlated with bed availability in inpatient unit. The inpatient unit in hospital has several classes where the low-class of room tends to have more bed than the high-class of room that can be correlated to the length of stay (LOS). Purpose: The aim of this study was to analyze the admission time, discharge time and patient discharge type with LOS in Yellow Zone of ED. Method: The study consisted of 133 respondents. This was an analytical observational study with cross sectional design. Admission time, discharge time and patient discharge type was analyzed using Eta test. Results: The bivariate results identified the correlation between independent variables with the LOS of patient in Yellow Zone of ED. In Eta test, could be categorized to have a significant correlation if $\mathrm{F}$ count was more than $\mathrm{F}$ table. Conclusion: There was a significant correlation between the admission time, discharge time and patients discharge type with LOS of patients in the Yellow Zone of ED.
\end{abstract}

Keywords: Emergency Departments, Length of Stay, Admission Time, Discharge Time, Patients Discharge Type

\section{INTRODUCTION}

Patient density in Emergency Department (ED) is an issue that is still being experienced in various countries. Patients density commonly refers to overcrowding that will cause some problems, one of which is the Length of Stay (LOS) of patient in ED. The prolongation of LOS will cause problems for patients (increased mortality and morbidity) and also the staff. The staff who are exhausted also will potentially perform medical mistake that will adversely affect the patient (Salway et al., 2017).

Every year, one of the largest ED in Indonesia has increased the patient's admission. Data of patient's visit that have been obtained from the previous study revealed that ED which have the highest number of visits is in the Yellow Zone, thus, yellow zone has great potential in variation of LOS (Ahsan, Deviantony \& Setyoadi, 2017). The number of patients in ED cannot be predicted. Moreover, as the patient's condition is unforeseen in ED so patient's admission time is various. Not only on shift hour but other factors are associated with LOS of admitted patients in ED (Bashkin et al., 2015; Hosseininejad et al., 2017; Johns et al., 2017).

Patients discharge type have correlation with the incidence of LOS in ED. Patients discharge type from ED are categorized into 3 types, if they are outpatients, patients who are transferred into hospital ward and 
patients who are transferred in intensive care. Among the three types of patients discharge type from the ED and their correlation factor for each of them are not same (Chaou et al., 2016).

There are differences in celerity between patients who are transferred at certain hours (Hosseininejad et al., 2017; Wertheimer et al., 2015). Patients who are discharged before 12 pm (Discharge Before Noon) will increase the number of empty beds in the inpatient unit and patients in ED can be moved soon. Discharge process has correlation with the length of doctor's evaluation towards the patient in each case of hospitalization (Liu, Phillips \& Codde, 2001; White \& Glazier, 2011). Late afternoon hospital discharges cause crowding during admission, as a result the patient will not be transferred to the inpatient unit from $3 \mathrm{pm}$ to $8 \mathrm{pm}$ (Rabin et al., 2012; Wertheimer et al., 2015).

According to the phenomenon above, there are still doubts regarding the variable admission time, discharge time and patients discharge type and its correlated with the LOS of patients in the ED, especially in Yellow Zone. Therefore the aim of this study was to analyze the admission time, discharge time and patient discharge type with LOS of patient in the Yellow Zone.

\section{METHODOLOGY}

This study was an analytical observational study using cross sectional design. The data collection was done from January to February 2019. The study was conducted in one of the ED of hospital in Indonesia, particularly in the Yellow Zone.

The sampling technique used was non-probability sampling with consecutive sampling design whereas the calculation technique of sample in this study was done using the rule of thumb. The total number was 133 respondents.

All statistical analysis was performed using SPSS. Eta test was used to correlate the independent variables and dependent variable. The result was evaluated on Eta test and categorized that independent variables and independent variables had significant correlation if $\mathrm{F}$ count was more than $\mathrm{F}$ table.

\section{RESULTS}

Distribution of Respondent Characteristic and Univariate Analysis

Table 1: Distribution of Respondent Characteristic by Gender

\begin{tabular}{|l|c|c|}
\hline Variable & $\mathbf{n}$ & $\mathbf{\%}$ \\
\hline Gender & & \\
\hline Male & 81 & 60.9 \\
\hline Female & 52 & 39.1 \\
\hline
\end{tabular}

According to table 1, most of the respondents were male as many as $81(60.9 \%)$ while the female respondents were $52(39.1 \%)$.

Table 2: Distribution of Respondent Characteristic by Age, Number of patients per shift and LOS

\begin{tabular}{|l|c|c|c|}
\hline \multicolumn{1}{|c|}{ Variable } & N & Min - Max & Mean \pm SD \\
\hline Age & 133 & $1-89$ & $46.18 \pm 23.08$ \\
\hline Patient/Shift & 133 & $11-38$ & $25.48 \pm 5.29$ \\
\hline LOS & 133 & $186-1685$ & $753.59 \pm 339.41$ \\
\hline
\end{tabular}

According to table 2, the youngest age of respondent was 1 year old and the oldest was 89 years old. The least number of patients in ED in one shift was 11 patients and the highest number of patients in one shift were 38 patients. The fastest LOS of patients obtained 186 minutes (3.1 hours) and the longest LOS of patients obtained 1685 minutes ( 28 hours).

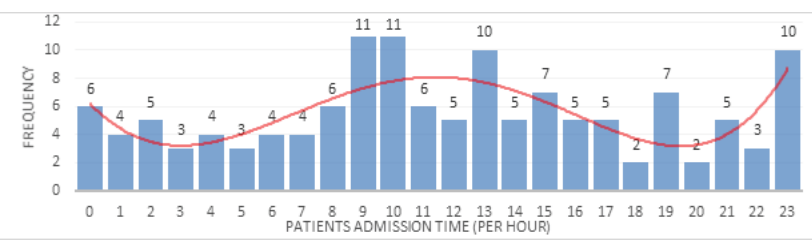

Figure 1: Univariate Analysis of Patients Admision Time

According to figure 1, most of the respondents came between 9 am to 11:00 am, as many as 11 respondents $(8.3 \%)$ while the fewest respondents came on between 6 pm to $9 \mathrm{pm}$, as many as 2 respondents $(1.5 \%)$.

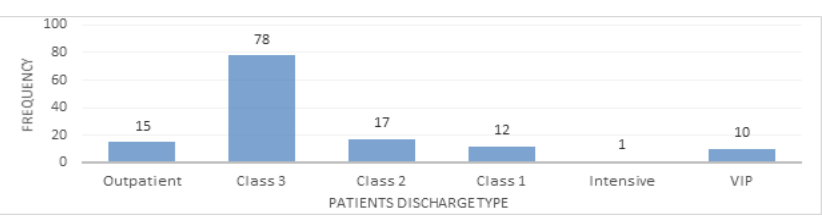

Figure 2: Univariate Analysis of Patients Discharge Type

According to diagram figure 2, most of patients 
discharge type in Yellow Zone of ED during the study conducted was into Class 3 as many as 78 respondents $(58.6 \%)$ while the fewest of patients discharge type was into intensive care as many as 1 patient $(0.8 \%)$.

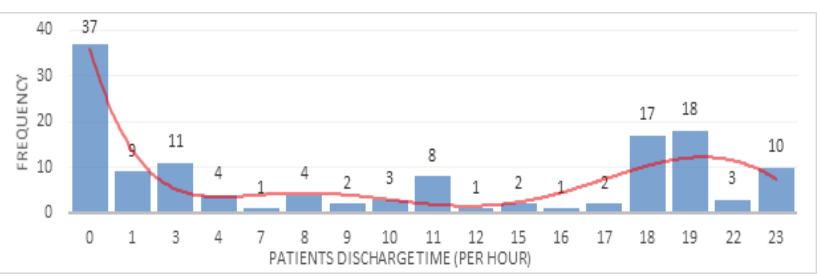

Figure 3: Univariate Analysis of Patients Discharge Time

According to figure 3 , most of respondent discharged at 00:00 am to $1 \mathrm{pm}$ as many as 37 respondents $(27.8 \%)$, and there was no respondents $(0 \%)$ discharged at 2 am to $10 \mathrm{am}$.

\section{Bivariate Analysis}

In this study, bivariate analyzes was conducted by using Eta test and obtained the following results:

\section{Table 3: Bivariate Analysis Result of Eta Test}

\begin{tabular}{|l|c|c|c|}
\hline Variable & Eta r Corelation & F Count & F Table \\
\hline TimePA & 0.784 & 7.547 & 1.65 \\
\hline TypePD & 0.529 & 9.882 & 2.31 \\
\hline TimePD & 0.484 & 2.217 & 1.75 \\
\hline
\end{tabular}

TimePA $=$ Patients Admision Time

TypePD $=$ Patients Discharge Type

Time $P D=$ Patients Discharge Time

According to table 3 explained that there was significant correlation between the three of independent variables with dependent variable (length of stay) indicated by the F-count value were more than F-table.

Variable of admission time had correlation value of 0.784 , this result meant that the correlation was strong because this value was between the range of 0.600 to 0.800 .

Variable of patient discharge types and discharge time had correlation value under the variable of admission time with a value of 0.529 and 0.484 , this result meant that the correlation was moderate because the value was between the range of 0.400 to 0.600 .
Table 4: The Average LOS (AVLOS) between Inpatients and Outpatients

\begin{tabular}{|c|c|c|c|}
\hline Variable & $\mathbf{n}$ & AVLOS & $\sum$ Mean AV LOS \\
\hline Inpatient & & & \multirow{6}{*}{923} \\
\hline VIP & 10 & 1068 & \\
\hline Intensive & 1 & 941 & \\
\hline Class 1 & 12 & 1206 & \\
\hline Class 2 & 17 & 730 & \\
\hline Class 3 & 78 & 670 & \\
\hline Outpatient & 15 & 628 & 628 \\
\hline
\end{tabular}

According to table 4 explained that inpatient has the longest AVLOS and Total Mean AVLOS than outpatient.

\section{DISCUSSION}

\section{Description of LOS of Patients in ED}

The results of this study found that the AVLOS of Patient in Yellow Zone of ED was 753.59 minutes (12.5 hours) with the fastest time of 186 minutes (3.1 hours) and the longest time of 1685 minutes (28 hours). There were differences AVLOS of patients in Yellow Zone of ED obtained by standards recommended in Indonesia which applied LOS should be $<8$ hours, thus LOS of patients in Yellow Zone of ED extended to 4.5 hours.

During the study, there was significant increase in patient visit. In 2018 patients coming to the Yellow Zone of ED had an average visit of 2082 patients while in January 2019 there were 2584 patients. This will not only make the ED full of patients, but also the inpatient unit will become full correlated with LOS (Salway et al., 2017).

\section{Correlation between Admission Time and LOS}

Based on the bivariate test result by using Eta test obtained that the value of $F$ count (7.547) was more than F table (1.65) which shown that there were statistically significant correlations between the admission time with LOS in the Yellow Zone of ED. The strength of the correlation obtained at the value of 0.784 which indicated positive correlation. It explains that at certain admission time the patient has the long duration of LOS and /or at certain hours of admission time the patient also has short duration of LOS with strong correlation. Increased patient in this study peaked at 9 to 10 and at midnight on $11 \mathrm{pm}$. This increase in patients both in the morning and midnight caused an increase in the number of nurses. This had an impact on increasing LOS of patients. 
The correlation on this analysis maybe due to the fact that the average admission time was between 9 am to $10 \mathrm{am}$ and $11 \mathrm{pm}$. But the average of discharge time was at $6 \mathrm{pm}$ to $7 \mathrm{pm}$ and $12 \mathrm{am}$ at night. Patients who come in the morning and after complete observation cannot be transferred as the inpatient room was still full and only available in the afternoon or evening.

The results of this study is similar with a study which stated that patients who come in certain hours also had correlation with LOS of patients in the ED especially during the increase in patient visiting hour (Hosseininejad et al., 2017; Johns et al., 2017)

Not only the patient density that might be correlated with LOS, but the admission time also could be correlated with LOS. Thus ED was overcrowded actually due to the lengthening of LOS with patients admitted in certain hours.

\section{Correlation between Patients Discharge Type with LOS}

Based on the bivariate test results by using Eta test showed that the value of F count (9.882) was more than F table (2.31). Thus there was statistically significant correlation between the transfer type with LOS of patients in the Yellow Zone of ED. The strength of the correlation was obtained at the value of 0.529 which indicated positive correlation with the strength of the correlation being moderate. It explained that on certain patients discharge type had the same LOS and/or on certain patients discharge type also had the same LOS celerity with the level of correlation being moderate. Most of patients discharge type in the Yellow Zone of ED was into Class 3 as many as 78 respondents and the fewest patients discharge type was into intensive care as many as 1 respondent.

The correlation on this analyzes results could be caused by outpatient were likely not going to wait for the availability of bed in inpatient unit, based on the results of the study also revealed that patients who discharged into higher class would have a high LOS because of the number of beds was fewer compared with low-class of room.

These results were supported by research data in Table 4 in which the outpatients had an AVLOS of 628 minutes, patients who were transferred to the class $3 \mathrm{had}$ an AVLOS of 670 minutes, the patient who was transferred to the class 2 had an AVLOS of 730 minutes, the patient who was transferred to the class 1 had an AVLOS of 1206 minutes, patients who were transferred to intensive care only 1 patient had an AVLOS of 941 minute and patients who were transferred to VIP had AVLOS of 1068 minutes. According to table 4, total average of inpatient AVLOS was longer than the total average of outpatient AVLOS.

These results same with the study that explained that there was significant difference in the AVLOS that was found between inpatient (Mean $=544$ minutes, SD $=323$ minutes $)$ and outpatient $($ mean $=291$ minutes, $S D$ $=286$ minutes). This proven that if ED carry out more discharged inpatient compared with outpatients, it would lengthened the LOS of patients in the ED (Chaou et al., 2016).

In addition, patients with a demand for higher class room would lengthening their LOS. By providing feedback to the patient to move in lower class room was the best solution. The patients would also be able to book a room with higher class while in the inpatient unit rather than having to wait in the ED that made ED became full and make treatment not maximum.

\section{Correlation between Patients Discharge Time with LOS}

Based on the bivariate test results by using Eta test showed that $\mathrm{F}$ count (2.217) was more than the F table (1.75) which proved that there were statistically significant correlations between the admission time with LOS of patients in Yellow Zone of ED. The strength of the correlation obtained a value of 0.484 which indicated that positive correlation with the strength of the correlation being moderate. This explains that at certain patient discharge time the patient has the long duration of LOS and/or at certain hours of patient discharge time the patient also has short duration of LOS with moderate correlation. This result was similar to a study that revealed there was a difference in celerity between the patients who were transferred at certain hours (Talleshi et al., 2014; Wertheimer et al., 2015).

The correlation on this analyses results could be caused by the average admission time of patient that come on 9 am to 10 am and the average patient was transferred into the inpatient unit at $0 \mathrm{am}$. The distance between 10 am to 0 am was 14 hours ( 840 minutes). This result was supported with the average of LOS that was 
753.59 minutes (12.5 hours). Besides this was also correlated with the fullness of inpatient unit, patients who come in the morning and observation details was completed so they were ready to be transferred but apparently inpatient unit was only available in the afternoon or evening. This caused in the average patient transfer at $6 \mathrm{pm}$ to $7 \mathrm{pm}$ and at $0 \mathrm{am}$. The transfer of patients in these hours was not unreasonable, nurses transferred patients during these timings as the inpatient unit had empty rooms during this period.

By knowing the transfer time of patient from the ED into the inpatient unit at certain hours would indicate that at that time usually patients in the inpatient unit discharged (El-Eid et al., 2015). Most of the transfer time of patients was at 0 am to $12 \mathrm{am}$, the result was in contrast to a study that explained that patients who were discharged before $12 \mathrm{pm}$ would increase the number of empty beds in the inpatient unit and patients in the ED could soon be transferred, patients in the inpatient unit were discharged before $12 \mathrm{pm}$ would increase the celerity of patients discharge time from the ED and would soon be transferred at $3 \mathrm{pm}$ to 8:00 pm (Rabin et al., 2012; Wertheimer et al., 2015).

A study revealed that patients in the inpatient unit who were not immediately discharged as they had to wait to perform the tests. They were forced to wait until test results come in. This delayed doctor in discussing clinical case to clinical decision making (including a decision to discharge the patients) and the difficulty of getting specialized consultation in the inpatient unit. This would make patients in the ED late transfer and they were discharged much after $12 \mathrm{pm}$ (da Silva et al., 2014).

These kinds of varied results might be due to the patient's density in the ED in January 2019 causing overcrowded both in the ED and in the inpatient unit. Thus, the ED did not have opportunity to immediately transfer the patient into the inpatient unit. In addition, the process of discharging patients was correlated with doctor's evaluation of patients that resulted in late transfer of each patient in the inpatient unit. This could make a patient in the ED to be transferred to the inpatient unit at $3 \mathrm{pm}$ to $8 \mathrm{pm}$. (Rabin et al., 2012; Wertheimer et al., 2015). Doctors visit inpatient unit which more than $12 \mathrm{pm}$ would make the LOS of patients in the ED increased since the ED would soon have an increase the patient visit that starting from 11 am until $5 \mathrm{pm}$.

\section{IMPLICATIONS}

Patients who are admitted during the crowded hours such as morning shift between 9 am to 10 am should be transferred into inpatient unit of class 3 and if patient wanted to move to other classes, then could be processed after patient were shifted to inpatient unit.

The patient discharge time on this result could be used as references in particular to develop policies of centralized bed control. This strategy was used to prepare the discharge of patients in the inpatient unit before $12 \mathrm{pm}$ to reduce the LOS of patient in the Yellow Zone of ED. Indirectly, it was expected that the visit of the doctor in the inpatient unit must also be controlled by a policy so as to conduct a visit in the inpatient room before $12 \mathrm{pm}$ (before noon).

\section{CONCLUSION}

The AVLOS of Patient in the Yellow Zone of ED was 753.59 minutes (12.5 hours). Thus the AVLOS extended to 4.5 hours. All variables had correlation with LOS. Therefore in order to reduce LOS of patient, required the availability of inpatient bed continuously.

\section{REFERENCES}

Bashkin, O., Caspi, S., Haligoa, R., Mizrahi, S. \& Stalnikowicz, R. (2015). Organizational factors affecting length of stay in the emergency department: Initial observational study. Israel Journal of Health Policy Research, 4(1), pp 1-7.

Chaou, C.H., Chiu, T.F., Yen, A.M.F., Ng, C.J. \& Chen, H.H. (2016). Analyzing Factors Affecting Emergency Department Length of Stay-Using a Competing Risk-Accelerated Failure Time Model. Medicine (United States), 95(14).

da Silva, S.A., Valácio, R.A., Botelho, F.C. \& Amaral, C.F.S. (2014). Reasons for discharge delays in teaching hospitals. Revista de Saude Publica, 48(2), pp 314-321. 
Ahsan, A., Deviantony, F. \& Setyoadi, S. (2017). Analysis of the Associated Factors of Boarding Time in Yellow Zone Patients in Emergency Department. Jurnal Ners, 12(2), pp 261-266.

El-Eid, G.R., Kaddoum, R., Tamim, H. \& Hitti, E.A. (2015). Improving Hospital Discharge Time. Medicine (Baltimore), 94(12), pp 633.

Talleshi, Z., Hosseininejad, S.M., Khatir, G., Bozorghi, F., Gorji, A.M. \& Gorji, M.A. (2014). The effect of new emergency program on patient length of stay in a teaching hospital emergency department of Tehran. Nigerian Medical Journal, 55(2), pp 134-138.

Hosseininejad, S.M., Aminiahidashti, H., Pashaei, S.M., Khatir, I.G., Montazer, S.H., Bozorgi, F. \& Mahmoudi, F. (2017). Determinants of Prolonged Length of Stay in the Emergency Department; a Cross-sectional Study. Emergency, 5(1), pp 53.

Johns, K., Smith, S., Karreman, E. \& Kastelic, A. (2017). P067: Factors associated with prolonged length of stay of admitted patients in a tertiary care emergency department. Canadian Journal of Emergency Medicine, 19(S1), pp 101.

Liu, Y., Phillips, M. \& Codde, J. (2001). Factors influencing patients' length of stay. Australian Health Review : $A$ Publication of the Australian Hospital Association, 24(2), pp 63-70.

Rabin, E., Kocher, K., McClelland, M., Pines, J., Hwang, U., Rathlev, N., Asplin, B., Trueger, N.S. \& Weber, E. (2012). Solutions to emergency department "boarding" and crowding are underused and may need to be legislated. Health Affairs (Project Hope), 31(8), pp 1757-1766.

Salway, R., Valenzuela, R., Shoenberger, J., Mallon, W. \& Viccellio, A. (2017). Emergency Department (ED) Overcrowding: Evidence-Based Answers to Frequently Asked Questions. Revista Médica Clínica Las Condes, 28(2), pp 213-219.

Wertheimer, B., Jacobs, R.E.A., Iturrate, E., Bailey, M. \& Hochman, K. (2015). Discharge before noon: Effect on throughput and sustainability. Journal of Hospital Medicine, 10(10), pp 664-669.

White, H.L. \& Glazier, R.H. (2011). Do hospitalist physicians improve the quality of inpatient care delivery? A systematic review of process, efficiency and outcome measures. BMCMedicine, 9, pp 1-22. 